\title{
Pengaruh Kelebihan Berat Badan terhadap Kualitas Spermatozoa Tikus Wistar (Rattus Norvegicus)
}

\author{
${ }^{1}$ Swens A. Rompis \\ ${ }^{2}$ Lydia E. N. Tendean \\ ${ }^{2}$ Janette M. Rumbajan
}
${ }^{1}$ Program Studi Pendidikan Dokter Fakultas Kedokteran Universitas Sam Ratulangi Manado
${ }^{2}$ Bagian Biologi Fakultas Kedokteran Universitas Sam Ratulangi
Email: Swensv@ymail.com

\begin{abstract}
Overweight men usually had abnormal hormone regulation that can reduce the quality of spermatozoa. This study was aimed to determine the effect of overweight on the spermatozoa quality of Wistar rats (Rattus norvegicus). This was an experimental study with a post-test only control group design. Dependent variable in this study was spermatozoa quality consisting of concentration, motility, and morphology, meanwhile the independent variable was overweight in Wistar rats. Subjects were 10 male Wistar rats divided into two groups: experimental group $\left(\mathrm{P}_{1}\right)$, which was the group with overweight, and the control group $\left(\mathrm{P}_{0}\right)$, the group with normal weight. Treatment was given for 50 days. Based on the statistical analysis performed, the results showed significant differences in concentration, motility, and morphology of the spermatozoa between the experimental group and the control group. For all spermatozoa quality parameters, the $P$-values were less than 0.05 . Conclusion: Overweight affected the quality of Wistar rat spermatozoa.
\end{abstract}

Keywords: overweight, spermatozoa quality

\begin{abstract}
Abstrak: Pada pria dengan kelebihan berat badan biasanya terjadi regulasi hormon abnormal yang dapat menurunkan parameter kualitas spermatozoa. Penelitian ini bertujuan untuk mengetahui pengaruh kelebihan berat badan terhadap kualitas spermatozoa tikus Wistar (Rattus norvegicus). Jenis penelitian ialah eksperimental dengan post test only control group design. Variabel tergantung dalam penelitian ini ialah kualitas spermatozoa yang meliputi konsentrasi, motilitas, dan morfologi sedangkan variabel bebas ialah kelebihan berat badan pada tikus Wistar. Subjek penelitian sebanyak 10 ekor tikus Wistar jantan dibagi menjadi dua kelompok yaitu kelompok perlakuan $\left(\mathrm{P}_{1}\right)$ yang merupakan kelompok dengan kelebihan berat badan dan kelompok kontrol $\left(\mathrm{P}_{0}\right)$ yang merupakan kelompok dengan berat badan normal. Perlakuan diberikan selama 50 hari. Berdasarkan analisis data yang dilakukan, hasil penelitian menunjukkan adanya perbedaan bermakna pada konsentrasi, motilitas, dan morfologi spermatozoa kelompok perlakuan dan kontrol, dimana untuk semua parameter kualitas spermatozoa didapatkan nilai $P<0,05$. Simpulan: Terdapat pengaruh bermakna dari kelebihan berat badan terhadap kualitas spermatozoa tikus Wistar.
\end{abstract}

Kata kunci: kelebihan berat badan, kualitas spermatozoa

Pria dengan kelebihan berat badan sering didapatkan penurunan konsentrasi, serta motilitas, dan morfologi yang abnormal pada spermatozoa. Hal ini dikarenakan terjadi regulasi hormon abnormal akibat peningkatan jumlah jaringan adiposa.
Regulasi hormon abnormal yang terjadi menyebabkan peningkatan estrogen dan penurunan testoteron yang akan memengaruhi spermatogenesis. ${ }^{1}$ Kelebihan berat badan adalah suatu kondisi medis berupa kelebihan lemak tubuh yang terjadi karena 
ketidakseimbangan antara asupan makanan yang masuk dengan pengeluaran energi oleh tubuh. ${ }^{2}$ Prevalensi kelebihan berat badan di Indonesia cenderung mengalami peningkatan. Menurut Riset Kesehatan Dasar (Riskesdas) 2013, prevalensi kelebihan berat badan untuk kelompok usia diatas 18 tahun ialah sebesar 19,7\%, dengan prevalensi tertinggi berada di Provinsi Sulawesi Utara sebesar 34,7\%. ${ }^{3}$

Pria dengan kelebihan berat badan lebih berisiko menjadi tidak subur dibandingkan pria dengan berat badan normal. ${ }^{4-6}$ Hasil penelitian Martini et al. ${ }^{5}$ menunjukkan bahwa pria dengan kelebihan berat badan memiliki lebih sedikit sperma aktif daripada pria berbadan kurus. Hasil penelitian ini mendukung bahwa terdapat efek buruk yang ditimbulkan kelebihan berat badan terhadap kualitas spermatozoa. Penelitian lain yang dilakukan oleh Vignera et al. ${ }^{6}$ menegaskan bahwa pria dengan kelebihan berat badan memiliki jumlah spermatozoa dengan motilitas dan morfologi normal yang lebih rendah dibandingkan pria dengan berat badan normal. Palmer et al. $^{7}$ menyatakan bahwa pada orang dengan kelebihan berat badan didapatkan interaksi antara jaringan adiposa dan regulasi hormon serta interaksi antara jaringan adiposa dan suhu testis yang pada akhirnya berpengaruh terhadap beberapa parameter kualitas spermatozoa yang meliputi konsentrasi, motilitas, dan morfologi dari spermatozoa.

Penelitian ini bertujuan untuk mengetahui pengaruh kelebihan berat badan terhadap kualitas spermatozoa dengan menggunakan tikus Wistar (Rattus norvegicus).

\section{METODE PENELITIAN}

Jenis penelitian ini ialah eksperimental dengan post test only control group design. Penelitian dilakukan di Laboratorium Bagian Biologi Fakultas Kedokteran Universitas Sam Ratulangi Manado dengan rentang waktu penelitian selama 50 hari dari bulan September-November 2017. Variabel yang diteliti dalam penelitian ini yaitu kelebihan berat badan pada tikus
Wistar (Rattus norvegicus) sebagai variabel bebas dan kualitas spermatozoa yang meliputi konsentrasi, motilitas, dan morfologi sebagai variabel tergantung. Kriteria inklusi pengambilan hewan coba terdiri dari tikus Wistar (Rattus norvegicus) jantan, umur 12-15 minggu, berat badan normal 150-200 gram dan berat badan berlebih > 200 gram. Kriteri eksklusi yaitu hewan coba tampak sakit, tidak bergerak secara aktif, dan mati saat penelitian. Penelitian ini terdiri dari satu kelompok kontrol dan satu kelompok perlakuan. Analisis data yang dilakukan ialah uji normalitas, uji homogenitas, dan uji tindependen.

Subyek penelitian ialah 5 ekor tikus Wistar jantan, berusia 12-15 minggu dengan berat badan 150-200 gr untuk kelompok berat badan normal dan 5 ekor lainnya, berusia 12-15 minggu dengan berat badan >200 gr untuk kelompok kelebihan berat badan. Bahan-bahan lainnya ialah pelet komersial, air ledeng, larutan $\mathrm{NaCl} 0,9 \%$, safranin, metanol, kristal violet, dan akuades. Alat-alat yang digunakan ialah kandang pemeliharaan, bilik hitung haemasitometer Improved Neubauer, dissecting kit, objek gelas, gelas penutup, pipet tetes, cawan Petri, kapas, counter, mikroskop listrik, kamera, dan timbangan.

Proses aklimatisasi dilakukan selama 1 minggu. Tikus Wistar ditempatkan dalam kandang terbuat dari bahan plastik yang ditutup dengan kawat kasa. Pada dasar kandang diletakkan sekam dan diganti setiap 3 hari, terutama bila sekam basah. Pelet komersial dan air ledeng diberikan setiap harinya untuk makanan dan minuman hewan coba. Kelompok perlakuan $\left(\mathrm{P}_{1}\right)$ diberikan makanan dengan porsi yang lebih besar dan kelompok kontrol $\left(\mathrm{P}_{0}\right)$ diberikan makanan dengan porsi normal. Makanan diberikan sebanyak 1 kali per hari dengan porsi makan normal sebanyak 20 gr sedangkan porsi makan yang lebih banyak diberikan kepada kelompok perlakuan yaitu sebanyak 20-22 gr. Perlakuan tersebut dilakukan selama 50 hari. Pada hari ke 51, hewan coba diterminasi dengan pembedah- 
an menggunakan dissecting kit untuk mengambil organ reproduksi berupa testis dan kauda epididimis yang kemudian dipisahkan dengan cara memotong bagian proksimal korpus epididimis dan bagian distal vas deferens. Potongan kauda epididimis dimasukkan ke dalam cawan Petri, lalu diteteskan 3 tetes larutan $\mathrm{NaCl}$ $0,9 \%$.

Suspensi spermatozoa yang telah diperoleh terlebih dahulu dihomogenkan dengan cara diaduk dengan gelas pengaduk. Selanjutnya suspensi spermatozoa dihisap dengan pipet leukosit sebanyak 0,5 ml sampel, setelah itu hisap cairan pengencer dalam pipet sampai tanda 11 . Suspensi spermatozoa diteteskan pada bilik hitung hemasitometer Improved Neubauer lalu diamati dibawah mikroskop dengan pembesaran 400 kali. Cara penghitungan spermatozoa dilakukan dengan membagi 1 lapang pandang menjadi 4 kuadran, kemdian dihitung jumlah spermatozoa yang terdapat dalam masing-masing kuadran. Setelah itu dijumlahkan total spermatozoa yang terdapat dalam setiap kuadran dan dikalikan 50.000.

Suspensi spermatozoa diteteskan pada kaca objek dengan volume tertentu (tidak lebih dari 10 mikroliter) kemudian ditutup dengan kaca penutup, diiarkan 1 menit agar stabil kemudian diamati dengan mikroskop pembesaran 400 kali kemudian dinilai motilitas spermatozoa. Untuk kategori motilitas spermatozoa terdiri atas: motilitas A, gerakan spermatozoa maju lurus dan cepat (progresif); motilitas B, gerakan spermatozoa bergerak ditempat (non progresif); dan motilitas $\mathrm{C}$, spermatozoa diam atau tidak bergerak. Diperiksa 4-6 lapangan pandang untuk mendapatkan 100 spermatozoa secara berurutan, kemudian diklasifikasikan sehingga menghasilkan persentase setiap kategori motilitas.

Suspensi spermatozoa diteteskan di atas kaca objek, dibuat preparat hapus dan dikeringkan di udara. Selanjutnya sediaan hapus difiksasi dengan metanol selama 5 menit, kemudian dikeringkan. Setelah kering, sediaan hapus dilakukan pewarnaan dengan safranin selama 5 menit, kemudian preparat dibilas dengan air mengalir. Sediaan hapus diwarnai dengan kristal violet selama 1 menit. Setelah itu, sediaan dibilas dan dikeringkan kemudian diamati di bawah mikroskop dengan pembesaran 100 kali kemudian 400 kali. Diambil tiga lapang pandang untuk menentukan persentase morfologik spermatozoa normal dan abnormal pada satu preparat dan dicatat bentuk/kelainan tiap spermatozoa pada setiap lapang pandang dan yang terakhir hitung persentase morfologi spermatozoa yang normal dan abnormal.

\section{HASIL PENELITIAN}

\section{Konsentrasi spermatozoa}

Setelah diberikan porsi makanan yang lebih banyak daripada porsi normal selama 50 hari pada tikus Wistar (Rattus norvegicus) didapatkan perbedaan rerata konsentrasi spermatozoa antara kelompok $\mathrm{P}_{1}$ dibandingkan dengan kelompok $\mathrm{P}_{0}$. Rerata konsentrasi spermatozoa $\mathrm{P}_{1}$ lebih rendah yaitu sebanyak $48,6 \times 10^{6}$ sperma $/ \mathrm{ml}$ suspensi dibandingkan dengan $\mathrm{P}_{0}$ sebanyak $112,4 \times 10^{6}$ sperma/ml suspensi (Tabel 1).

Tabel 1. Konsentrasi spermatozoa tikus Wistar (Rattus norvegicus)

\begin{tabular}{cc}
\hline $\begin{array}{c}\text { Kelompok } \\
\text { sampel }\end{array}$ & $\begin{array}{c}\text { Konsentrasi } \\
\text { spermatozoa }(\mathbf{x 1 0} / \mathbf{m L})\end{array}$ \\
\hline $\mathrm{P}_{0}$ & 112,4 \\
$\mathrm{P}_{1}$ & 48,6 \\
\hline
\end{tabular}

\section{Motilitas spermatozoa}

Pemeriksaan motilitas spermatozoa dibagi menjadi motilitas kategori A, B, dan C. Hasil penelitian mendapatkan perbedaan rerata motilitas spermatozoa kategori $\mathrm{A}$, kategori $\mathrm{B}$, dan kategori $\mathrm{C}$ pada kelompok $\mathrm{P}_{1}$ dan $\mathrm{P}_{0}$. Rerata motilitas spermatozoa kelompok $\mathrm{P}_{1}$ memiliki kategori A sebesar $12,8 \%$, Kategori B sebesar 44,4\%, dan Kategori C sebesar 42,4\%, sedangkan rerata motilitas spermatozoa kelompok $\mathrm{P}_{0}$ memiliki kategori A sebesar 21\%, kategori B sebesar $64 \%$ dan kategori C sebesar $15 \%$ (Tabel 2). 
Tabel 2. Motilitas spermatozoa tikus Wistar (Rattus norvegicus)

\begin{tabular}{cccc}
\hline $\begin{array}{c}\text { Kelompok } \\
\text { sampel }\end{array}$ & $\mathrm{A}(\%)$ & $\begin{array}{c}\text { Motilitas } \\
\mathrm{B}(\%)\end{array}$ & $\mathrm{C}(\%)$ \\
\hline $\mathrm{P}_{0}$ & 21 & 64 & 15 \\
$\mathrm{P}_{1}$ & 12,8 & 44,4 & 42,4 \\
\hline
\end{tabular}

\section{Morfologi spermatozoa}

Pemeriksaan morfologi spermatozoa tikus Wistar dibagi menjadi morfologi normal dan abnormal. Terdapat perbedaan rerata morfologi spermatozoa normal dan abnormal antara kelompok $\mathrm{P}_{1}$ dibandingkan dengan kelompok $\mathrm{P}_{0}$. Rerata morfologi spermatozoa normal $\mathrm{P}_{1}$ sebesar $55,2 \%$ dan abnormal sebesar $44,8 \%$ sedangkan untuk rerata morfologi spermatozoa normal $\mathrm{P}_{0}$ sebesar $71,6 \%$ dan abnormal sebesar $28,4 \%$ (Tabel 3).

Tabel 3. Morfologi spermatozoa tikus Wistar (Rattus norvegicus)

\begin{tabular}{ccc}
\hline $\begin{array}{c}\text { Kelompok } \\
\text { sampel }\end{array}$ & $\begin{array}{c}\text { Morfologi } \\
\text { normal } \\
(\boldsymbol{\%})\end{array}$ & $\begin{array}{c}\text { Morfologi } \\
\text { abnormal } \\
(\boldsymbol{\%})\end{array}$ \\
\hline $\mathrm{P}_{0}$ & 71,6 & 28,4 \\
$\mathrm{P}_{1}$ & 55,2 & 44,8 \\
\hline
\end{tabular}

\section{Uji komparabilitas antar kelompok penelitian}

Uji komparabilitas dilakukan untuk membandingkan rerata kualitas spermatozoa yaitu konsentrasi spermatozoa, motilitas spermatozoa, dan morfologi spermatozoa antar kelompok penelitian yaitu $\mathrm{P}_{1}$ dan $\mathrm{P}_{0}$.

Berdasarkan hasil uji normalitas dan homogenitas, didapatkan data terdistribusi normal dan homogen, maka analisis komparatif yang dilakukan ialah uji tindependen.

Hasil uji t-independen terhadap kelompok perlakuan dan kontrol mendapatkan nilai $P<0,05$ pada perbandingan konsentrasi $(0,001)$, motilitas A $(0,012)$, motilitas B $(0,021)$, motilitas C $(0,002)$, dan morfologi normal $(0,016)$ yang berarti terdapat perbedaan bermakna rerata konsentasi, motilitas, dan morfologi antara kelompok perlakuan dan kontrol (Tabel 4).
Tabel 4. Perbandingan kualitas spermatozoa kelompok perlakuan $\left(\mathrm{P}_{1}\right)$ dan kontrol $\left(\mathrm{P}_{0}\right)$

\begin{tabular}{lccc}
\hline $\begin{array}{c}\text { Kualitas } \\
\text { spermatozoa }\end{array}$ & $\mathbf{P}_{\mathbf{1}}$ & $\mathbf{P}_{\mathbf{0}}$ & Nilai $\boldsymbol{P}$ \\
\hline Konsentrasi & 48,6 & 112,4 & 0,001 \\
Motilitas A & 12,8 & 21 & 0,012 \\
Motilitas B & 44,4 & 64 & 0,021 \\
Motilitas C & 42,4 & 15 & 0,002 \\
$\begin{array}{l}\text { Morfologi } \\
\text { normal }\end{array}$ & 55,2 & 71,6 & 0,016 \\
\hline
\end{tabular}

\section{BAHASAN}

\section{Konsentrasi spermatozoa}

Berdasarkan uji komparabilitas menggunakan uji t-independen (Tabel 4), didapatkan nilai $P=0,001$ artinya terdapat pengaruh perlakuan terhadap konsentrasi spermatozoa tikus Wistar (Rattus norvegicus). Hal ini sesuai dengan penelitian sebelumnya yang dilakukan Paasch et al. ${ }^{8}$ di Liepzig Jerman yang melibatkan 2157 pria dengan usia antara 20 hingga 30 tahun. Hasil yang didapatkan ialah pada kelompok usia yang sama, pria dengan kelebihan berat badan secara umum memiliki jumlah spermatozoa yang lebih rendah disbandingkan pria dengan berat badan normal. Secara keseluruhan, memang jumlah spermatozoa pria dengan kelebihan berat badan lebih rendah daripada pria dengan berat badan normal namun, masih dalam kisaran normal, yaitu antara 20-150 juta/ml.

\section{Motilitas spermatozoa}

Pada Tabel 2 terdapat rerata perbedaan motilitas spermatozoa dari $\mathrm{P}_{1}$ dan $\mathrm{P}_{0}$. Untuk rerata motilitas $\mathrm{A}, \mathrm{P}_{1}$ sebesar $12,8 \%$ lebih rendah dibandingkan $\mathrm{P}_{0}$ sebesar $21 \%$. Untuk rerata motilitas $\mathrm{B}, \mathrm{P}_{1}$ sebesar $44,4 \%$ lebih rendah dibandingkan $\mathrm{P}_{0} 64 \%$. Untuk rerata motilitas $\mathrm{C}, \mathrm{P}_{1}$ sebesar $42,4 \%$ lebih tinggi dibandingkan $\mathrm{P}_{0}$ sebesar $15 \%$.

Berdasarkan uji komparabilitas menggunakan uji t-independen (Tabel 4), untuk motilitas $\mathrm{A}, \mathrm{B}$, dan $\mathrm{C}$ didapatkan nilai sig berturut-turut ialah $(P=0,012), \quad(P=0,021)$ dan $(P=0,002)$; kesemua nilai $P<0,05$ yang menunjukkan terdapat pengaruh perlakuan terhadap motilitas spermatozoa tikus Wistar (Rattus norvegicus). 
Hal ini sesuai dengan penelitian yang dilakukan Martini et al. ${ }^{5}$ yang menunjukkan pengaruh kelebihan berat badan terhadap kualitas spermatozoa dalam hal ini motilitas normal spermatozoa. Dari serangkaian tes, didapatkan hasil yaitu pria dengan kelebihan berat badan memiliki lebih sedikit spermatozoa aktif daripada pria dengan berat badan normal.

\section{Morfologi spermatozoa}

Tabel 3 menampilkan rerata perbedaan morfologi spermatozoa dari kelompok kontrol dan kelompok perlakuan. Untuk rerata morfologi normal, kelompok perlakuan sebesar 55,2\% yang lebih rendah dari kelompok kontrol sebesar 71,6\%. Untuk rerata morfologi abnormal, kelompok perlakuan sebesar $44,8 \%$ lebih tinggi dari kelompok kontrol sebesar 28,4\%.

Berdasarkan uji komparabilitas menggunakan uji t-independen (Tabel 4), untuk morfologi normal dan abnormal didapatkan nilai $P$ berturut-turut ialah $P=0,016$ dan $P=$ 0,016 ; kedua nilai $P<0,05$ yang menunjukkan terdapat pengaruh perlakuan terhadap morfologi spermatozoa tikus Wistar (Rattus norvegicus).

Hal ini sejalan dengan penelitian yang dilakukan Vignera et al. ${ }^{6}$ yang menyatakan bahwa pria dengan kelebihan berat badan cenderung memiliki motilitas dan bentuk normal spermatozoa yang lebih rendah dibandingkan pria dengan berat badan normal. Menurut Hofny et al. ${ }^{9}$ kelebihan berat badan berkorelasi positif dengan morfologi spermatozoa abnormal artinya semakin tinggi berat badan seseorang maka semakin tinggi pula morfologi spermatozoa yang abnormal, serta berkorelasi negatif dengan konsentrasi dan motilitas spermatozoa artinya semakin tinggi berat badan seseorang maka semakin rendah konsentrasi dan motilitas spermatozoa.

Secara keseluruhan, penurunan kualitas spermatozoa yang ditemukan dalam penelitian ini dapat disebabkan oleh kelebihan berat badan. Pada kelebihan berat badan terjadi peningkatan massa jaringan adiposa yang kemudian bersama dengan sel Leydig akan memroduksi enzim sitokrom
P450 aromatase. Enzim ini bertanggung jawab mengubah sebagian testosteron yang dikeluarkan oleh testis menjadi estrogen sehingga menyebabkan terjadinya regulasi hormon yang abnormal dengan tingkat estrogen lebih tinggi dibandingkan testosteron. ${ }^{10,11}$

Keadaan diatas telah lama dikaitkan dengan penurunan beberapa parameter kualitas spermatozoa terutama konsentrasi spermatozoa dengan dua mekanisme potensial. Pertama, peningkatan konsentrasi estrogen intratestikular hingga mencapai ambang batas yang memiliki efek buruk pada spermatogenesis (mekanisme testis lokal). Kedua, peningkatan sirkulasi estrogen mengakibatkan penekanan fungsi hipotalamus-hipofisis (mekanisme perifer) sehingga menyebabkan gangguan sekresi FSH yang akan berpengaruh pada spermatogenesis. $^{12}$

Penyebab lainnya penurunan parameter kualitas spermatozoa pada kelebihan berat badan dapat disebabkan oleh peningkatan panas gonad yang terjadi akibat adipositas skrotum yang meningkat. Efek buruk dari peningkatan panas tersebut sering dikaitkan dengan penurunan beberapa parameter spertmatozoa yang meliputi konsentrasi, motilitas dan morfologi spermatozoa. ${ }^{11}$

\section{SIMPULAN}

Berdasarkan hasil penelitian ini dapat disimpulkan bahwa kelebihan berat badan berpengaruh terhadap kualitas spermatozoa tikus Wistar (Rattus norvegicus) berupa penurunan kualitas spermatozoa dibandingkan kelompok dengan berat badan normal.

\section{SARAN}

Diharapkan dapat dilakukan penelitian lebih lanjut mengenai pengaruh kelebihan berat badan terhadap kualitas spermatozoa dengan jumlah sampel yang lebih banyak dan waktu penelitian yang lebih lama.

Disarankan untuk menjaga pola hidup sehat antara lain menjaga berat badan ideal. Selain untuk menjaga kualitas sperma bagi pria juga sekaligus bermanfaat bagi aspek kesehatan lainnya. 


\section{DAFTAR PUSTAKA}

1. Bullen MV, Judge S. The impact of obesity on male fertility. British Journal of Obesity. 2015;1:99-107.

2. Breakthrough-generation. Obesitas. 2017 [cited 2017 Aug 12]. Available from: http://www.breakthroughgeneration.com/info/berita/Penyakit/19 2

3. Badan Penelitian dan Pengembangan Kesehatan Kementerian Kesehatan RI. Riset Kesehatan Dasar Tahun 2013. 2013 [cited 2017 Aug 12]. Available from: www.depkes.go.id/resources/ download/general/Hasil\%20Riskesdas \%202013.pdf

4. Harnowo PA-detikHealth. Pria gemuk spermanya sedikit dan tidak bagus. 2012. [cited 2017 Aug 12]. Available from: https://health.detik.com/ read/ 2012/03/14/175922/1867455/763/priagemuk-spermanya-sedikit-dan-tidakbagus

5. Martini AC, Tissera ABS, Estofan DMD, Rosa I, Molina BS, Mangeaud A, et al. Overweight and seminal quality: a study of 749 patients. Fertility and Sterility. 2010;94:1739-43.

6. Vignera SL, Condorelli RA, Vicari E, Calogero AE. Negative effect of increased body weight on sperm conventional flow cytometric sperm parameters. Journal of Andrology. 2010;33:53-8.

7. Palmer NO, Bakos HW, Fullston T, Lane M. Impact of obesity on male fertility, sperm function and molecular composition. Spermatogenesis. 2012; 2(4):253-63.

8. Paasch U, Grunewald S, Kratzsch J, Glander HJ. Obesity and age effect male fertility potential. Fertil Steril. 2010;94(7):2898-901.

9. Hofny ERM, Ali ME, Abdel-Hafez HZ, Kamal EE, Mohamed EE, El-Azeem HGA, et al. Semen parameters and hormonal profile in obese fertile and infertile males. Fertil Steril. 2010; 94(2):581-4.

10. Sherwood L. Fisiologi Manusia dari Sel ke Sistem (6th ed) (Terjemahan). Jakarta: ECG, 2011; p. 822.

11. Katib A. Mechanisms linking obesity to male infertility. Central Europan Journal of Urology. 2015; 68(1):79-85.

12. Hammoud AO, Griffin J, Meikle AW, Gibson M, Peterson CM, Carrell DT. Association of aromatase repeat polymorphism length and the relationship between obesity and decreased sperm concentration. Hum Reprod. 2010; 25(12):3146-51. 